\title{
Some current challenges facing the athlete and their doctor
}

CPD

Shane P Brun

\section{Background}

Primary care physicians are often responsible for the care of people involved in sporting and exercise activities at various competitive levels. Issues confronting the athlete and their primary care physician are the potentially serious risks, responsibilities and challenges facing those involved with sport and physical activity.

\section{Objective}

The aim of this article is to address three of the most important challenges currently facing the athlete and primary care physician caring for athletes. The challenges are to recognise the potential risks to the athlete of sustaining a sudden cardiac arrest, sports-related concussion or doping violation in sport, as each of these have serious implications for life, wellbeing, performance and/or reputation. Education and risk mitigation are also essential components of care that will be addressed.

\section{Discussion}

The primary care physician caring for athletes has a pivotal role in ensuring appropriate screening, education and ongoing surveillance to minimise the potentially serious risks facing those involved with physical activity.
THE TERM 'ATHLETE' appears in more than 30,000 titles or abstracts among all PubMed-indexed articles, although it remains unclear where and when this term originated. When searching in the same database by 'athlete definition' or 'definition of athlete', not a single citation has been found. ${ }^{1}$ To have an unambiguous definition, Araujo et al have provided the following, which will be used within this article. To be an athlete, four criteria should be simultaneously fulfilled:

- to be training in sports aiming to improve his/her performance or results

- to be actively participating in sport competitions

- to be formally registered in a local, regional or national sport federation as a competitor

- to have sport training and competition as his/her major activity or focus of interest, almost always devoting several hours in all or most of the days to these sport activities, exceeding the time allocated to other professional or leisure activities. ${ }^{1}$

\section{Challenges}

Some of the more significant challenges facing both the primary care physician and athlete are being able to identify the risks to the athlete of sustaining a sudden

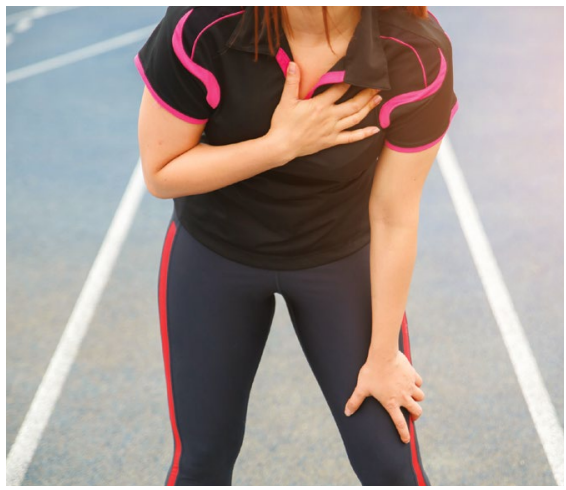

cardiac arrest (SCA), recognising a sportsrelated concussion (SRC) and attempting to eliminate doping violation in sport. Additional challenges facing the older athlete have previously been addressed. ${ }^{2}$

\section{Sudden cardiac arrest}

\section{Incidence}

Sudden cardiac death (SCD) in sport has a likely incidence of $1: 50,000$ to $1: 80,000$ athletes per year. ${ }^{3}$ The incidence is higher in males and certain ethnic groups. ${ }^{4}$ SCD comprises $16 \%$ of all deaths of athletes, which is more than the percentage of deaths attributed to suicide, drug overdose and heat stroke combined. ${ }^{3}$ It has been estimated that the incidence of SCD in athletes is twice that of the general population. ${ }^{5}$

Obtaining accurate figures for SCD and SCA is difficult. Not all cases are reported, some are misclassified and many studies looking at the incidence had inclusion criteria so varied that it was difficult to accurately comment on significance; therefore, the true incidence may only be speculated and remains unclear. ${ }^{6}$ As a result of this categorical uncertainty, within this article, the terms SCA and SCD will be collectively referred to as SCA.

The distribution of cardiac disease and incidence is variable by country. ${ }^{7}$ 


\section{Causes}

Although the most common causes of SCA in athletes are somewhat speculative, ${ }^{6}$ it appears that some common causes within various age groups fit a pattern, as outlined in Table 1. This table should be viewed in the context of there being significant overlap in the conditions leading to SCA within the different age groups. In athletes aged $<35$ years, inherited and/ or congenital heart disease are among the more common causes, whereas atherosclerotic coronary artery disease continues to have the highest incidence in athletes aged $>35$ years. ${ }^{8,9}$ In addition to age, other factors that contribute to SCA include sex, lifestyle, race and ethnicity. ${ }^{3-9}$ There are causes of SCA that are not particular to any age group; some of these are outlined in Table 2.

In primary care, there is a presumed high level of awareness regarding the prevention, detection and management of atherosclerotic coronary disease, with somewhat less awareness of the inherited and/or congenital heart diseases.

It is important to note that, with the exception of myocardial ischaemia and hypertrophic cardiomyopathy, chest pain is a rare feature of many of the cardiac conditions leading to SCA in young people. Subsequently, the absence of chest pain is not a reliable or valid rule-out criterion when assessing SCA risk.

\section{Screening}

The focused history is an essential component to support a correct diagnosis. Family history and any associated conditions such as diabetes and elevated body mass index always warrant further investigation.

Antecedent symptoms and family history may be absent in over $80 \%$ of cases of SCA,${ }^{10}$ making screening somewhat difficult albeit essential.

Any symptoms of excessive breathlessness, light-headedness, chest pain, irregular heartbeat or syncope with physical activity are potential red flags that must never be ignored. No person experiencing these symptoms must ever be allowed to continue with physical activity without first receiving a thorough cardiac assessment and subsequent clearance to continue their activity.
A resting 12-lead electrocardiogram (ECG) is an essential baseline investigation for anyone in any age group with clinical suspicion and for all people over the age of 35 years involved or planning involvement in a physical activity. For elite and professional athletes of any age, a periodic resting 12-lead ECG is mandatory prior to competition in most sporting codes.

The majority of disorders associated with an increased risk of SCA are suggested or identified by abnormalities on a resting 12-lead ECG, ${ }^{11,12}$ most often identified with abnormalities of the ST and/or T waves. The fact that a normal athlete ECG can differ from a normal non-athlete ECG makes ECG interpretation more difficult. Figure 1 outlines normal and abnormal athlete ECG patterns, with Figure 2 showing some examples of classical ECG findings. Figure 3 shows an example of a normal non-athlete ECG. Figures 4-7 show some classical features of abnormal ECG patterns.

Any ECG that is identified as abnormalparticularly those that have ST or T wave

Table 1. Potential causes of sudden cardiac arrest in the athlete by age

\begin{tabular}{|c|c|c|c|}
\hline & \multicolumn{3}{|c|}{ Age group } \\
\hline & $<16$ years & 16-35 years & >35 years \\
\hline Condition & Myocarditis & Hypertrophic cardiomyopathy & Ischaemic heart disease \\
\hline Potential cause & $\begin{array}{l}\text { Often secondary to viral or } \\
\text { bacterial infection }\end{array}$ & Most often inherited & $\begin{array}{l}\text { Adverse lifestyle factors } \\
\text { Inherited risks }\end{array}$ \\
\hline $\begin{array}{l}\text { Potential outcome resulting in } \\
\text { sudden cardiac arrest }\end{array}$ & $\begin{array}{l}\text { Arrhythmias, cardiac failure, } \\
\text { cardiogenic shock } \\
\text { May result in dilated } \\
\text { cardiomyopathy }\end{array}$ & Ventricular arrhythmias & $\begin{array}{l}\text { Ventricular fibrillation } \\
\text { Pulseless ventricular tachycardia } \\
\text { Asystole }\end{array}$ \\
\hline $\begin{array}{l}\text { Electrocardiographic findings } \\
\text { pre-event }\end{array}$ & $\begin{array}{l}\text { Sinus tachycardia } \\
\text { Non-specific ST segment and } \\
\text { T wave changes }\end{array}$ & $\begin{array}{l}\text { T wave inversion and } \\
\text { ST depression, usually in the } \\
\text { infero-lateral leads, or prominent } \\
\text { (wide) Q waves }\end{array}$ & $\begin{array}{l}\text { May be normal, or show ST } \\
\text { and/or T wave changes }\end{array}$ \\
\hline Potential symptoms pre-event & $\begin{array}{l}\text { Usually sub-clinical; shortness } \\
\text { of breath and tachycardia may } \\
\text { be present }\end{array}$ & $\begin{array}{l}\text { Most often asymptomatic } \\
\text { unless severe } \\
\text { If severe: } \\
\text { - breathlessness } \\
\text { - chest pain } \\
\text { - rapid or irregular heartbeats } \\
\text { - light-headedness } \\
\text { - syncope }\end{array}$ & $\begin{array}{l}\text { May be asymptomatic, or have: } \\
\text { - chest pain } \\
\text { - shortness of breath } \\
\text { (especially on exertion) } \\
\text { - light-headedness } \\
\text { - palpitations }\end{array}$ \\
\hline
\end{tabular}


Table 2. Potential causes of sudden cardiac arrest in all age groups

\begin{tabular}{|c|c|c|c|c|}
\hline & \multicolumn{4}{|c|}{ Condition } \\
\hline & Commotio cordis & Long QT syndrome & Brugada syndrome & $\begin{array}{l}\text { Wolff-Parkinson-White } \\
\text { syndrome }\end{array}$ \\
\hline Potential cause & $\begin{array}{l}\text { Direct impact to chest } \\
\text { overlying left ventricle } \\
\text { (precordium) }\end{array}$ & $\begin{array}{l}\text { Dysfunction of ion } \\
\text { channels located } \\
\text { in cardiac cells } \\
\text { (ion channelopathy) }\end{array}$ & $\begin{array}{l}\text { Dysfunction of ion } \\
\text { channels located } \\
\text { in cardiac cells (ion } \\
\text { channelopathy) }\end{array}$ & $\begin{array}{l}\text { Accessory electrical } \\
\text { pathway }\end{array}$ \\
\hline \multirow{2}{*}{$\begin{array}{l}\text { Potential outcome } \\
\text { resulting in sudden } \\
\text { cardiac arrest }\end{array}$} & $\begin{array}{l}\text { Primary arrhythmic event } \\
\text { (R-on-T phenomena) }\end{array}$ & Lethal arrhythmia & \multirow[t]{2}{*}{ Lethal arrhythmia } & \multirow[t]{2}{*}{ Lethal arrhythmia } \\
\hline & $\begin{array}{l}\text { Ventricular fibrillation } \\
\text { after impact }\end{array}$ & & & \\
\hline \multirow{5}{*}{$\begin{array}{l}\text { Electrocardiographic } \\
\text { findings pre-event }\end{array}$} & \multirow[t]{5}{*}{ Nil relevant prior to event } & May be normal & \multirow{5}{*}{$\begin{array}{l}\text { Coved ST segment } \\
\text { elevation }>2 \mathrm{~mm} \text { in }>1 \\
\text { of } \mathrm{V} 1-\mathrm{V} 3 \text { followed by a } \\
\text { negative } T \text { wave }\end{array}$} & May be normal \\
\hline & & Male athletes & & Short PR interval \\
\hline & & QTc $\geq 470 \mathrm{~ms}$ & & Wide QRS complex \\
\hline & & \multirow[t]{2}{*}{$\begin{array}{l}\text { Female athletes } \\
\text { QTc } \geq 480 \mathrm{~ms}\end{array}$} & & $\begin{array}{l}\text { Delta wave (slurring } \\
\text { of the initial portion } \\
\text { of QRS) }\end{array}$ \\
\hline & & & & $\begin{array}{l}\text { ST segment and } \\
\text { T wave discordance }\end{array}$ \\
\hline $\begin{array}{l}\text { Potential symptoms } \\
\text { pre-event }\end{array}$ & Nil & Majority asymptomatic & Majority asymptomatic & $\begin{array}{l}\text { Related to tachycardia: } \\
\text { - } \text { palpitations } \\
\text { - } \text { shortness of breath } \\
\text { - light-headedness } \\
\text { - fainting }\end{array}$ \\
\hline
\end{tabular}

abnormalities (such as in Figures 4-7) - should be considered suspicious. Referral for further interpretation and advice by a cardiologist experienced in the care of athletes is indicated. An echocardiogram should be considered as the next investigation to perform, ${ }^{13,14}$ and the patient should not be permitted to participate in physical activity until medically cleared.

\section{Management}

During physical activity, syncope or vasovagal episodes should never be considered as benign events. Therefore, an athlete who sustains a sudden syncope and collapse without impact or contact with another player or object must always be considered to have sustained an SCA until proven otherwise. In this situation, immediate response, early cardiopulmonary resuscitation and defibrillation are the priorities. If defibrillation is not immediately available, effective cardiac compression is the first priority. ${ }^{15}$ In an SCA, for every one-minute delay in defibrillation, the chance of return of spontaneous circulation decreases by $10 \% .^{16,17}$

\section{Sports-related concussion Background}

There is increasing attention, both through mainstream and social media as well as legal interest, on sports-related concussion (SRC). The primary care physician caring for concussed athletes has an ethical obligation to ensure that they safeguard the current and future physical and mental health of their patients. ${ }^{18}$

There is evidence showing the likely connection between repeated episodes of concussion and cognitive impairment, depression, suicide and chronic traumatic encephalopathy. ${ }^{18-22}$ Subsequently, SRC has become an area of significant concern and interest for athletes, sporting organisations, governments, the media and doctors.

The Consensus statement on concussion in sport has outlined the 11 'Rs' of SRC management: Recognise, Remove, Re-evaluate, Rest, Rehabilitation, Refer, Recover, Return to sport/school, Reconsider, Residual effects and sequelae, and Risk reduction. ${ }^{23}$ Table 3 outlines these stages. The approach to concussion assessment and management should be no different for the athlete and non-athlete populations.

\section{Definition}

SRC is a traumatic brain injury induced by biomechanical forces. Subsequently, the impact received to the head may be direct or indirect, and loss of consciousness may or may not be a feature. There is typically short-lived and potentially subtle impairment of neurological function that resolves spontaneously, although both the timeline and symptoms are variable and individual. It is important to note that the majority of SRCs occur without loss of consciousness or frank neurological signs. ${ }^{23}$ Standard structural neuroimaging studies typically fail to identify any abnormality. 


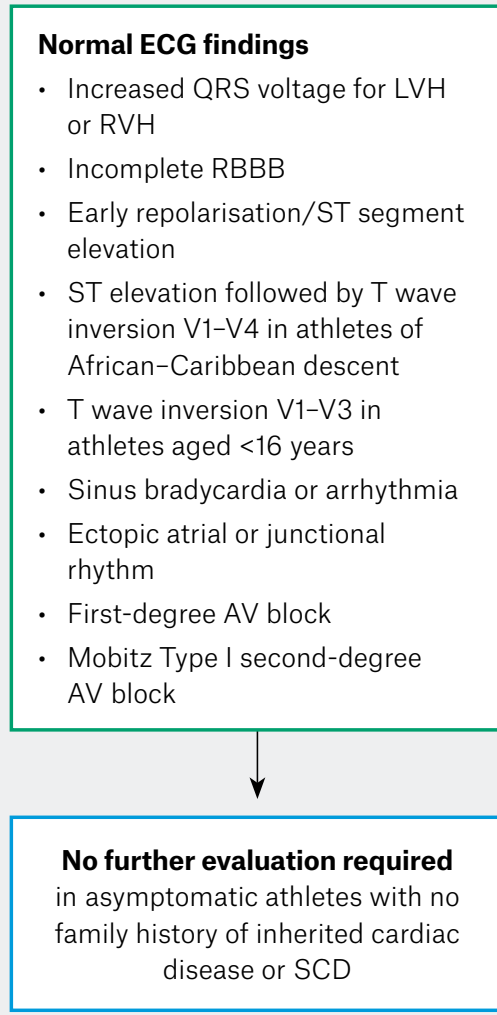

\section{Borderline ECG findings}

- Left axis deviation

- Left atrial enlargement

- Right axis deviation

- Right atrial enlargement

- Complete RBBB

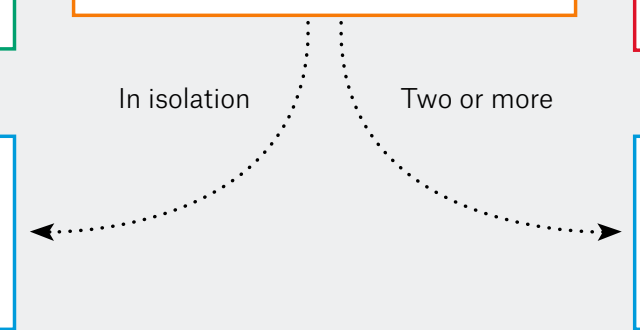

\section{Abnormal ECG findings}

- T wave inversion

- ST segment depression

- Pathological Q waves

- $Q R S \geq 140$ ms duration

- Epsilon wave

- Ventricular pre-excitation

- Prolonged QT interval

- Brugada Type 1 pattern

- Profound sinus bradycardia $<30 \mathrm{bpm}$

- $P R$ interval $\geq 400 \mathrm{~ms}$

- Mobitz Type II second-degree AV block

- Third-degree AV block

- $\geq 2$ PVCs

- Atrial tachyarrhythmias

- Ventricular arrhythmias

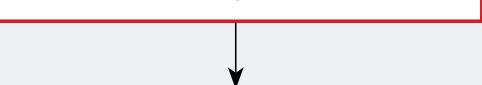

Further evaluation required to investigate for pathological cardiovascular disorders associated with SCD in athletes

Figure 1. International consensus standards for electrocardiographic interpretation in athletes ${ }^{12,39}$

$A V$, atrioventriular block; bpm, beats per minute; $E C G$, electrocardiogram; $L B B B$, left bundle branch block; $L V H$, left ventricular hypertrophy; $P V C$, premature ventricular contraction; $R B B B$, right bundle branch block; $R V H$, right ventricular hypertrophy; $S C D$, sudden cardiac death

\section{Diagnosis}

Currently there is no gold standard diagnostic tool for SRC, although there are accepted sideline screening tests including the Sports Concussion Assessment Tool, version 5 (SCAT5) ${ }^{23,24}$ for players aged $\geq 13$ years and the Child SCAT 5 for players aged $<13$ years. ${ }^{23,25}$ More detailed tests of cognitive and neurological function include the Maddocks questions ${ }^{26}$ and the Standardised Assessment of Concussion; ${ }^{27}$ the SCAT 5 is inclusive of both.

The SCAT 5 and Child SCAT 5 are designed only for use by doctors and licensed healthcare professionals, who must be familiar with both tools and how and when to apply and interpret them correctly.

In the sporting context, orientation questions involving time, place and person are unreliable ${ }^{26}$ and should not be used. Rapid sideline screening, rather than providing a definitive diagnosis, is the priority. The SCAT 5 and Child SCAT 5 are divided into on-field and off-field assessments, with the off-field assessment being more detailed.

In addition to the initial SCAT 5 or Child SCAT5, further assessment must always be performed. The re-assessment process includes a thorough clinical reassessment, determination of the need for neuroimaging and neuropsychological assessment using web-based tools such as CogSport or CogState. There is also a stepwise strategy for return to sport and/or school, which is outlined in SCAT5 and Child SCAT5.

\section{Management}

If a player experiences tonic posturing, loss of consciousness or balance disturbances, or if there is any suspicion of SRC, the player must always be removed from play, immediate medical management implemented and a more detailed assessment undertaken using the subsequent sections of the SCAT 5 or Child SCAT5.

Any player involved in a contact collapse who is unconscious or semi-lucid must be considered as having sustained a traumatic brain injury (TBI), spinal injury and potentially a compromised airway until proven otherwise and managed accordingly.

Following the diagnosis of an SRC, there should be a period of complete physical and cognitive rest for $24-48$ hours. After this 
initial phase, the patient may be encouraged to become gradually and progressively more physically and/or cognitively active, although they must remain below the threshold that provokes symptoms. This threshold is very variable and individual.

Rehabilitation following an SRC is dependent on the symptoms experienced, the stage following the injury and the athlete's individual demands. Rehabilitation should be multidisciplinary where possible, and consideration should be given to the physical, cognitive, psychological, social and individual needs of the athlete, as well as their sporting demands. Symptoms that are present after two weeks in an adult, and four weeks in a

\section{Table 3. The 11 'Rs' of sports-related concussion management ${ }^{23}$}

\begin{tabular}{ll}
\hline Stage & Action \\
\hline Recognise & Direct or indirect force to head \\
& Loss of consciousness not always a feature \\
& Assess memory, Glasgow Coma Scale and cervical spine \\
& Apply Sports Concussion Assessment Tool, version 5 (SCAT5) or \\
& Child SCAT5 \\
\hline Remove & If indicated by SCAT5 or Child SCAT5, immediately assess for \\
& red flags \\
& If any uncertainty, always remove from play \\
\hline Re-evaluate & Focused history and examination \\
& Determine the need for neuroimaging and neuropsychological \\
& assessment \\
Implement tools such as CogSport or CogState & Absolute cognitive and physical rest for 24-48 hours \\
following injury \\
Gradual and progressive reintroduction of physical and \\
cognitive activities \\
Aim is to remain asymptomatic \\
\hline
\end{tabular}

\begin{tabular}{ll}
\hline Rehabilitation & $\begin{array}{l}\text { Focused on specific symptoms experienced } \\
\text { Multidisciplinary } \\
\text { Includes physical, cognitive, psychological, social and sporting } \\
\text { needs of athlete }\end{array}$ \\
\hline Refer & $\begin{array}{l}\text { Symptoms still present after two weeks in an adult and four } \\
\text { weeks in a child } \\
\text { Multidisciplinary and experienced centre }\end{array}$ \\
\hline Recovery & $\begin{array}{l}\text { Severity of symptoms in the acute phase is the strongest } \\
\text { predictor of a slow recovery }\end{array}$ \\
\hline Return to sport/school & $\begin{array}{l}\text { Stepwise program according to SCAT5 or Child SCAT5 } \\
\text { Minimum of 24 hours in each step } \\
\text { Recurrence of symptoms mandates return to previous } \\
\text { asymptomatic step }\end{array}$ \\
\hline Reconsider & $\begin{array}{l}\text { Special considerations may apply to particular populations } \\
\text { including children and adolescents }\end{array}$ \\
\hline Residual effects/sequelae & $\begin{array}{l}\text { Increased risk of cognitive impairment, depression, suicide and } \\
\text { chronic traumatic encephalopathy }\end{array}$ \\
\hline Risk reduction & $\begin{array}{l}\text { Identify those with previous sports-related concussion and } \\
\text { attempt to mitigate risks }\end{array}$ \\
\hline & \\
\hline
\end{tabular}

child, following an SRC mandate referral. If possible, the athlete should be referred to a collaborative multidisciplinary facility skilled in managing SRC in such cases.

\section{When should the athlete return to sport?}

Graduated return to sport, school and/or work is a stepwise rehabilitation strategy and is outlined in the SCAT $5^{23,24}$ and Child SCAT $5 .{ }^{23,25}$ In general, each step of the strategy should take 24 hours to complete.

Progression through the stepwise program should therefore take a minimum of one week before return to usual activities. If concussion symptoms occur at any stage of the program, the athlete must step back to a stage at which they were completely symptom free and recommence progression from that stage.

Increased severity of the person's symptoms in the first 24-72 hours following injury (the acute phase) are the strongest predictor of a slow recovery. ${ }^{23}$ Determining complete recovery is difficult, and it is likely that the physiological and psychological time to recovery is much longer than clinical recovery time. That being said, the athlete must not return to pre-injury cognitive and physical exertion until completely symptom-free.

There is a paucity of literature available about the child and adolescent athlete with SRC, with the most appropriate assessment, management and return-to-sport strategy for the child or adolescent athlete yet to be defined. ${ }^{25}$ Until these are defined, the SCAT 5 and Child SCAT5 are the most appropriate screening tools currently available. It is expected that the duration of SRC symptoms is up to one month for the child and adolescent athlete. ${ }^{23}$

\section{Doping}

Doping in sport is a significant challenge for sporting and anti-doping authorities. It compromises the integrity of sport, increases the risk to personal safety and health for those who are doping, and has the potential to create an unfair advantage in training and competition. 


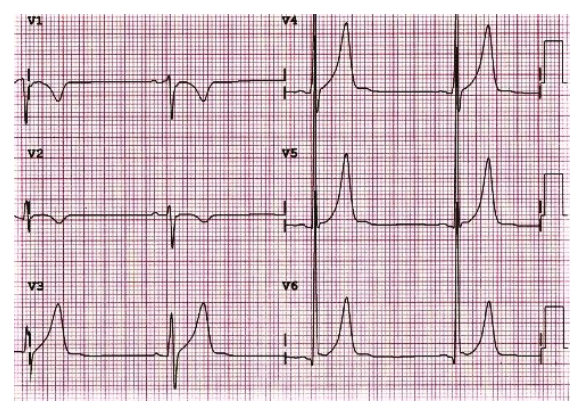

Increased QRS voltage criteria, suggestive of left ventricular hypertrophy ( $\mathrm{S}$ wave depth in $\mathrm{V} 1$ plus tallest $\mathrm{R}$ wave height in $\mathrm{V} 5-\mathrm{V} 6>35 \mathrm{~mm}$ )

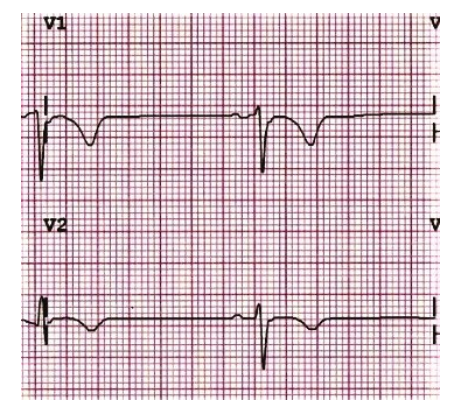

Convex ST segments; T wave inversion in leads other than aVR and possibly lead III

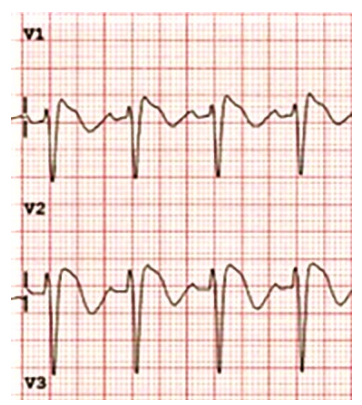

V1 and V2 demonstrating 'Brugada sign' followed by a negative T wave

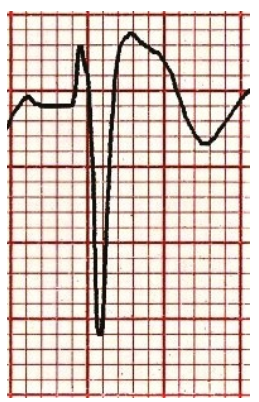

Coved (curved or dome like) ST elevation ('Brugada sign')

Figure 2. Typical electrocardiographic findings for the athlete

Figure 4. Electrocardiography findings for Brugada syndrome

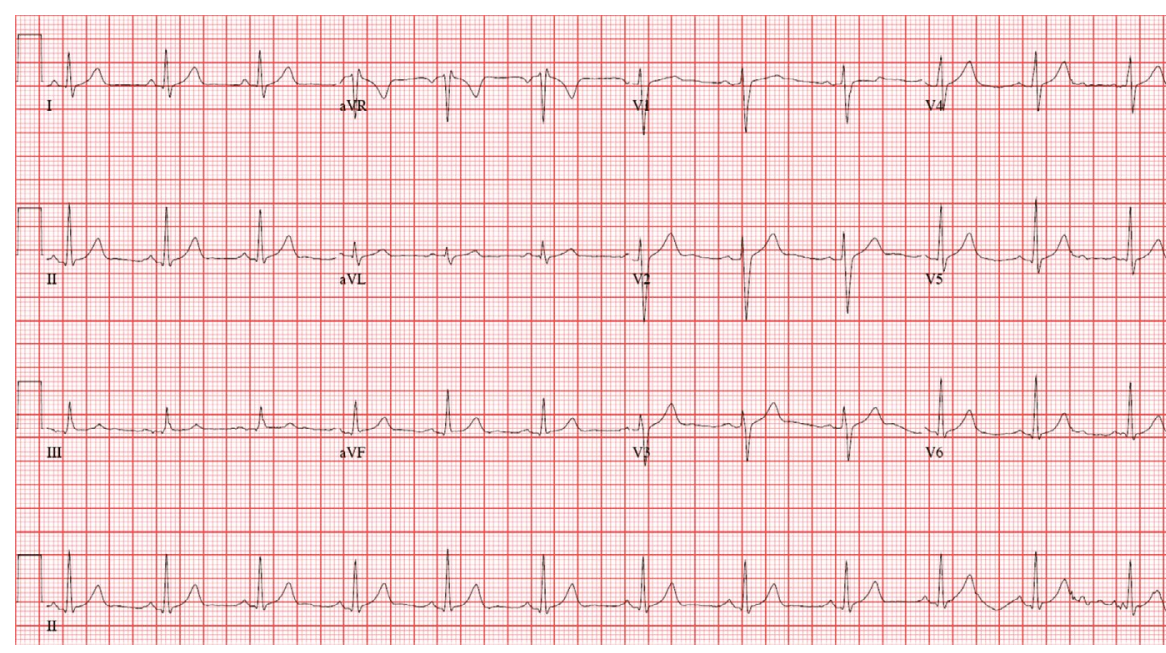

Figure 3. Example of a typical non-athlete electrocardiogram. Normal $T$ is upright except aVR and possibly III; T should follow orientation of QRS; R wave should elongate from V1-V6; QRS predominantly negative in V1-positive in V6; QRS should be narrow ( $<3$ small squares).

Many adverse analytical findings in athletes are unintentional and the result of consumption of supplements containing banned substances of which the athlete is unaware. The majority of these tainted supplements are classified as nutritional supplements, muscle-bulking agents, weight-reduction agents or health foods. These classifications downplay the potential risks these supplements may hold.

In a recent meta-analysis, substances prohibited by the World Anti-Doping Agency (WADA) were found in most of the supplements analysed. ${ }^{28}$ The most frequently encountered components in these products were anabolic steroids. ${ }^{29}$ In all cases, these substances were not listed on the product information for the supplement.

Consumption of supplements often starts at young age $\mathrm{e}^{30}$ and is encouraged by parents, coaches and peers. This paves the way for ongoing abuse and has been described as the 'gateway to doping'. ${ }^{31,32}$ Supplements that appear benign - such as vitamins, minerals, muscle-bulking agents and weight-loss products - are easily obtained either online or over the counter in supermarkets or pharmacies. The unregulated nature of online purchasing makes it particularly concerning.

Supplement use in athletes is likely to be higher than anticipated. Studies have suggested that the use of supplements in various sports ranges from $62 \%{ }^{33}$ to $88 \% .{ }^{34-37}$

Currently, in Australia, medicinal products such as herbs, vitamins, minerals, nutritional supplements, and homoeopathic and certain aromatherapy preparations are referred to as complementary medicines and are regulated as medicines under the Therapeutic Goods Act 1989 (www. legislation.gov.au/Series/C2004A03952). Some supplements may be classified as foods rather than medicines and therefore are categorised under the Australian and New Zealand Food Standards Code (www. foodstandards.gov.au/code/Pages/default. aspx), which is enforced by the states and territories and therefore has less strict regulation.

Although regulation is in place, currently this is only for products purchased within Australia. Australia uses a two-tiered system, with complementary medicines classified as 'lower risk medicines', which are not necessarily listed on the Australian Register of Therapeutic Goods (ARTG). Some complementary medicines are exempt from the requirement to be included on the ARTG.

With the current system in place and the ease of purchasing supplements 

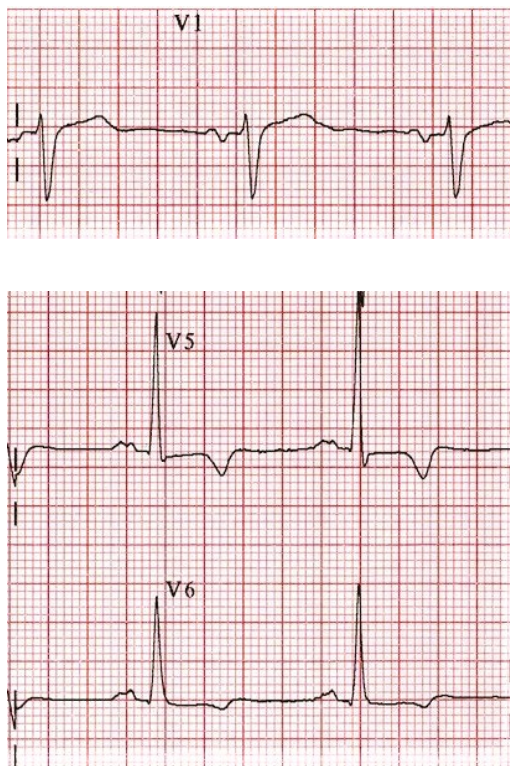

Increased QRS voltage criteria suggestive of left ventricular hypertrophy ( $\mathrm{S}$ wave depth in $\mathrm{V} 1$ and tallest $R$ wave height in $V 5-V 6>35 \mathrm{~mm}$ )
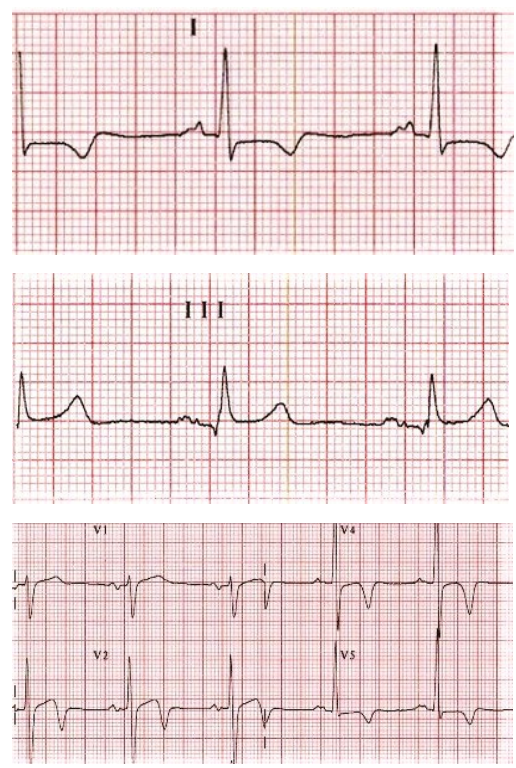

Nonspecific ST-T wave abnormalities

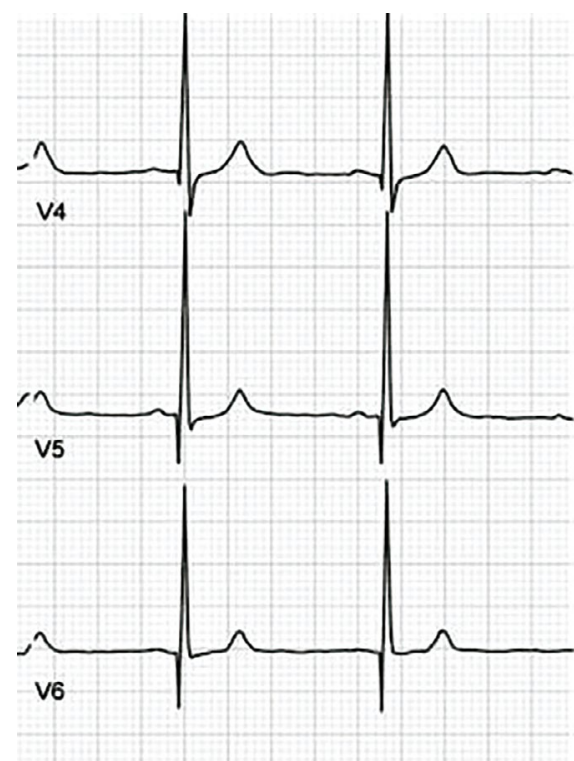

Narrow and deep Q waves that are 'dagger-like' in appearance

Figure 5. Some characteristic findings for hypertrophic cardiomyopathy on electrocardiography

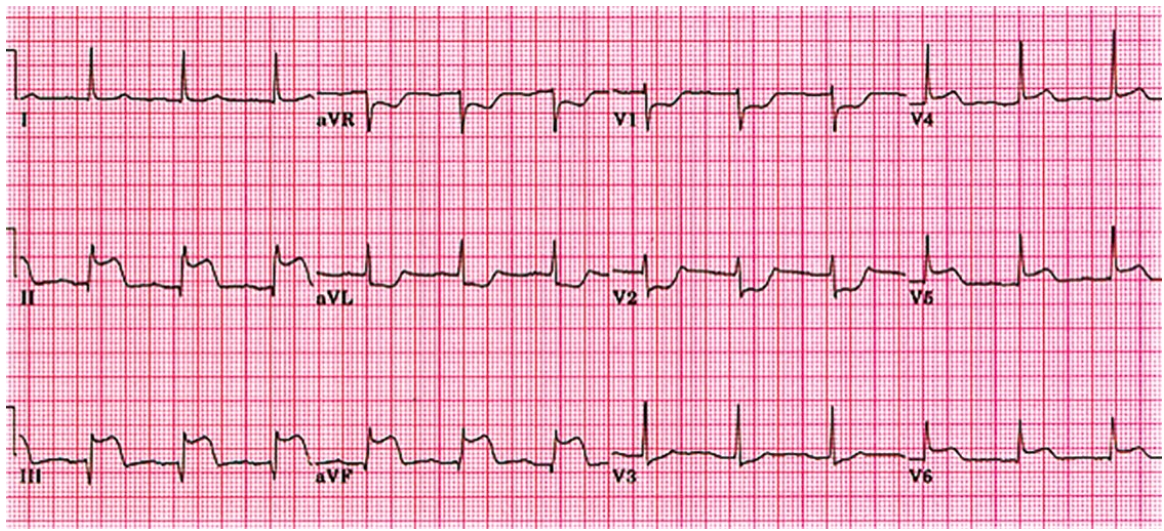

Figure 6. Example of electrocardiogram during an acute myocardial infarction, demonstrating ST segment elevation in leads II, III, aVF and V4-V6 with reciprocal ST changes in V1-V3

over the internet, there is a significant risk of supplements containing banned substances.

Most athletes consume supplements without consulting a physician ${ }^{38}$ and are likely to be unaware of the potential risks associated with supplement use. Although abiding by the WADA regulations is mandated for all athletes and is ultimately the athlete's responsibility, the physician should be aware of the likelihood that an athlete is taking supplements and the possibility of contamination with a banned substance.

The opportunity to educate the athlete about the health and doping risks associated with supplement use should be a priority for the physician. The WADA and Australian Sports Anti-Doping Authority websites provide valuable information and easy references for both the athlete and physician. Referral to an accredited sports dietitian is always appropriate when managing and educating athletes on performance, nutrition and supplementation.

\section{Key points}

- Anyone with any clinical suspicion and those aged $>35$ years involved or planning involvement in physical activity must, as a minimum, have a resting 12-lead ECG.

- Any ECG with ST and/or T wave changes not considered normal for the athlete or non-athlete must be considered as suspicious and referred for further investigation. The athlete must not participate in physical activity until medically cleared.

- Any athlete who is involved in a non-contact collapse and who is unconscious must be considered as having sustained an SCA until proven otherwise. Immediate priorities are cardiac compression and defibrillation.

- Unconsciousness is not necessarily a feature of SRC. 


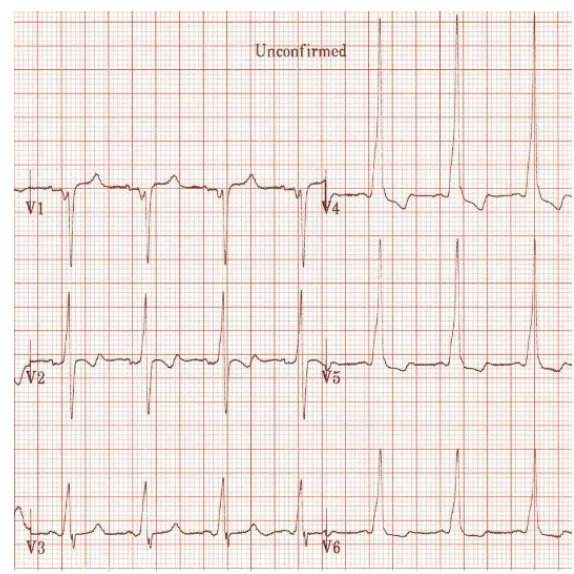

Short PR interval <120 msecs; QRS >100 msecs; delta wave

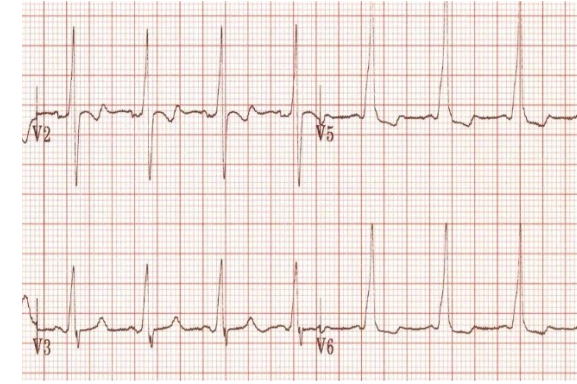

Delta waves seen as slurred upstroke at beginning of QRS
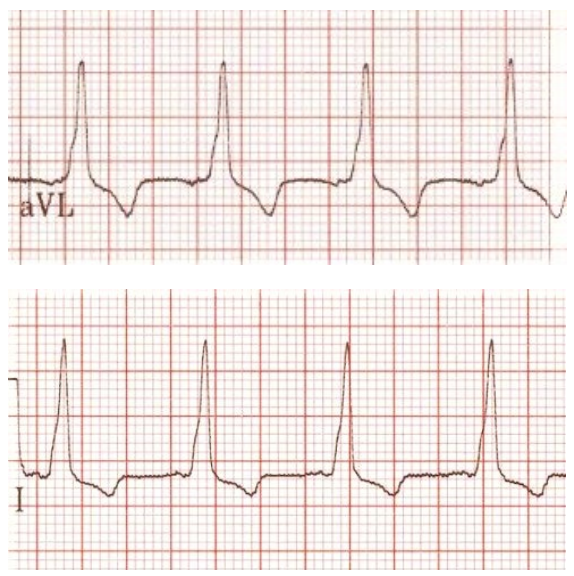

ST segment and T wave discordance

Figure 7. Possible electrocardiographic findings for Wolff-Parkinson-White syndrome

- People suspected of an SRC must always be removed from play and the SCAT 5 or Child SCAT5 applied.

- Any athlete involved in a contact collapse who is unconsciousness or semi-lucid must be considered as having sustained a TBI, spinal injury and the potential for a compromised airway until proven otherwise.

Immediate priorities are airway patency and spinal stabilisation.

- The majority of athletes take nutritional supplements without their doctor's knowledge.

- Supplement use is the leading cause for doping violations in sport.

- Many supplements contain substances that are banned in sport and not listed on the product information.

- The potential health risks associated with supplement use are significant.

\section{Resources}

- Sport Concussion Assessment Tool, 5th Edition, https://bjsm.bmj.com/content/ bjsports/early/2017/04/26/bjsports2017-097506SCAT5.full.pdf

- Child Sport Concussion Assessment Tool, 5th Edition, https://bjsm. bmj.com/content/bjsports/ early/2017/04/26/bjsports-2017097492childscat5.full.pdf
- World Anti-Doping Agency, www.wada-ama.org

- Australian Sports Anti-Doping Authority, www.asada.gov.au

\section{Author}

Shane P Brun MBBS, FFSEM (UK), FASMF, FACRRM, FRACGP, FARGP, MTrauma (Distinction), MSpMed, MEd, BAppSc, DCH, Associate Professor College of Medicine and Dentistry, James Cook University, QLD; Visiting Professor, Sports Medicine Unit, University of Malaysia, MY; Senior Medical Officer and Instructor, Fédération Internationale de Football Association (FIFA); $\mathrm{CH}$; Senior Medical Officer and Instructor, Asian Football Confederation (AFC), MY. shane.brun@jcu.edu.au

Competing interests: None.

Funding: None.

Provenance and peer review: Commissioned, externally peer reviewed.

\section{References}

1. Araújo CG, Scharhag J. Athlete: A working definition for medical and health sciences research. Scand J Med Sci Sports 2016;26(1):4-7. doi: 10.1111/sms.12632.

2. Brun SP. Clinical considerations for the ageing athlete. Aust Fam Physician 2016;45(7):478-83.

3. Harmon KG, Asif IM, Klossner D, Drezner JA. Incidence of sudden cardiac death in National Collegiate Athletic Association athletes. Circulation 2011;123(15):1594-600. doi: 10.1161/ CIRCULATIONAHA.110.004622.

4. Drezner JA, Harmon KG, Borjesson M. Incidence of sudden cardiac death in athletes: Where did the science go? Br J Sports Med 2011;45(12):947-48. doi: 10.1136/bjsports-2011-090077.

5. Corrado D, Basso C, Schiavon M, Thiene G. Screening for hypertrophic cardiomyopathy in young athletes. N Engl J Med 1998;339(6):364-69. doi: 10.1056/NEJM199808063390602.
6. Kong MH, Fonarow GC, Peterson ED, et al. Systematic review of the incidence of sudden cardiac death in the United States. J Am Coll Cardiol 2011;57(7):794-801. doi: 10.1016/j. jacc.2010.09.064.

7. Bohm P, Scharhag J, Meyer T. Data from a nationwide registry on sports-related sudden cardiac deaths in Germany. Eur J Prev Cardiol 2016;23(6):649-56 doi: $10.1177 / 2047487315594087$.

8. Corrado D, Schmied C, Basso C, et al. Risk of sports: Do we need a pre-participation screening for competitive and leisure athletes? Eur Heart J 2011;32(8):934-44. doi: 10.1093/eurheartj/ehq482.

9. Corrado D, Zorzi A. Sudden death in athletes. Int J Cardiol 2017;237:67-70. doi: 10.1016/j. ijcard.2017.03.034

10. de Noronha SV, Sharma S, Papadakis M, Desai S, Whyte G, Sheppard MN. Aetiology of sudden cardiac death in athletes in the United Kingdom: A pathological study. Heart 2009;95(17):1409-14. doi: 10.1136/hrt.2009.168369.

11. Sharma S, Drezner JA, Baggish A, et al. International recommendations for electrocardiographic interpretation in athletes. J Am Coll Cardiol 2017;69(8):1057-75. doi: 10.1016/j.jacc.2017.01.015.

12. Drezner JA, Sharma S, Baggish A, et al. International criteria for electrocardiographic interpretation in athletes: Consensus statement. Br J Sports Med 2017;51(9):704-31. doi: 10.1136/ bjsports-2016-097331.

13. Modaff DS, Hegde SM, Wyman RA, Rahko PS. Usefulness of focused screening echocardiography for collegiate athletes. Am J Cardiol. 2019;123(1):169-74. doi: 10.1016/j. amjcard.2018.09.012.

14. Yim ES, Basilico F, Corrado G. Early screening for cardiovascular abnormalities with preparticipation echocardiography: Utility of focused physicianoperated echocardiography in preparticipation screening of athletes. J Ultrasound Med 2014;33(2):307-13. doi: 10.7863/ultra.33.2.307.

15. Travers AH, Rea TD, Bobrow BJ, et al. Part 4: CPR overview: 2010 American Heart Association guidelines for cardiopulmonary resuscitation 
and emergency cardiovascular care. Circulation 2010:122(18 Suppl 3):S676-84. doi: 10.1161/ CIRCULATIONAHA.110.970913.

16. Rao P, Kern KB. Improving community survival rates from out-of-hospital cardiac arrest. Curr Cardiol Rev 2018;14(2):79-84 doi: 10.2174/1573403X14666180507160555.

17. Chan PS, Krumholz HM, Nichol G, Nallamothu BK. Delayed time to defibrillation after in-hospital cardiac arrest. N Engl J Med 2008;358(1):9-17. doi: 10.1056/NEJMoa0706467.

18. Kirschen MP, Tsou A, Nelson SB, et al. Legal and ethical implications in the evaluation and management of sports-related concussion. Neurology 2014:83(4):352-58. doi: 10.1212/ WNL.0000000000000613.

19. Manley G, Gardner AJ, Schneider KJ, et al. A systematic review of potential long-term effects of sport-related concussion. $\mathrm{Br} \mathrm{J}$ Sports Med 2017;51(12):969-77. doi: 10.1136/ bjsports-2017-097791.

20. Sariaslan A, Sharp DJ, D'Onofrio BM, Larsson $H$, Fazel S. Long-term outcomes associated with traumatic brain injury in childhood and adolescence: A nationwide Swedish cohort study of a wide range of medical and social outcomes. PLoS Med 2016;13(8):e1002103. doi: 10.1371/ journal.pmed.1002103.

21. Gavett BE, Stern RA, McKee AC. Chronic traumatic encephalopathy: A potential late effect of sport-related concussive and subconcussive head trauma. Clin Sports Med 2011;30(1):179-88, xi. doi: 10.1016/j.csm.2010.09.007.

22. Fralick M, Sy E, Hassan A, Burke MJ, Mostofsky E, Karsies T. Association of concussion with the risk of suicide: A systematic review and meta-analysis. JAMA Neurol 2019;76(2):144-51. doi: 10.1001/ jamaneurol.2018.3487.

23. McCrory P, Meeuwisse W, Dvořák J, et al. Consensus statement on concussion in sportthe 5(th) international conference on concussion in sport held in Berlin, October 2016. Br J Sports Med 2017;51(11):838-47. doi: 10.1136/ bjsports-2017-097699.

24. Echemendia RJ, Meeuwisse W, McCrory P, et al. The Sport Concussion Assessment Tool 5th edition (SCAT5): Background and rationale. Br J Sports Med 2017:51(11):848-50. doi: 10.1136/ bjsports-2017-097506.

25. Davis GA, Purcell L, Schneider KJ, et al. The Child Sport Concussion Assessment Tool 5th Edition (Child SCAT5): Background and rationale. Br J Sports Med 2017:51(11):859-61. doi: 10.1136/ bjsports-2017-097492.

26. Maddocks DL, Dicker GD, Saling MM. The assessment of orientation following concussion in athletes. Clin J Sport Med 1995;5(1):32-35.

27. McCrea M, Kelly JP, Randolph $\mathrm{C}$, et al. Standardized assessment of concussion (SAC) On-site mental status evaluation of the athlete. J Head Trauma Rehabil 1998;13(2):27-35.

28. Martinez-Sanz JM, Sospedra I, Ortiz CM Baladia E, Gil-Izquierdo A, Ortiz-Moncada R. Intended or unintended doping? A review of the presence of doping substances in dietary supplements used in sports. Nutrients 2017;9(10). pii:E1093. doi: 10.3390/nu9101093.

29. Parr MK, Fusshöller G, Schlorer N, et al. Detection of $\Delta 6$-methyltestosterone in a 'dietary supplement' and GC-MS/MS investigations on its urinary metabolism. Toxicol Lett 2011;201(2):101-04. doi: 10.1016/j.toxlet.2010.11.018.

30. Petróczi A, Aidman E. Psychological drivers in doping: The life-cycle model of performance enhancement. Subst Abuse Treat Prev Policy 2008;3:7. doi: 10.1186/1747-597X-3-7.
31. Kandel D, Kandel E. The Gateway Hypothesis of substance abuse: Developmental, biological and societal perspectives. Acta Paediatr 2015:104(2):130-37. doi: 10.1111/apa.12851.

32. Kandel DB, Yamaguchi K, Chen K. Stages of progression in drug involvement from adolescence to adulthood: Further evidence for the gateway theory. J Stud Alcohol 1992;53(5):447-57. doi: 10.15288/jsa.1992.53.447.

33. Nieper A. Nutritional supplement practices in UK junior national track and field athletes. Br J Sports Med 2005;39(9):645-49. doi: 10.1136/ bjsm.2004.015842.

34. Burns RD, Schiller MR, Merrick MA, Wolf KN Intercollegiate student athlete use of nutritional supplements and the role of athletic trainers and dietitians in nutrition counseling. J Am Diet Assoc 2004;104(2):246-49. doi: 10.1016/j. jada.2003.11.013.

35. Ziegler PJ, Nelson JA, Jonnalagadda SS. Use of dietary supplements by elite figure skaters. Int J Sport Nutr Exerc Metab 2003:13(3):266-76. doi: 10.1123/ijsnem.13.3.266.

36. Tscholl $P$, Alonso JM, Dollé $G$, Junge $A$, Dvorak J. The use of drugs and nutritiona supplements in top-level track and field athletes. Am J Sports Med 2010;38(1):133-40. doi: 10.1177/0363546509344071.

37. Hoffman JR, Faigenbaum AD, Ratamess NA, Ross R, Kang J, Tenenbaum G. Nutritional supplementation and anabolic steroid use in adolescents. Med Sci Sports Exerc 2008;40(1):15-24. doi: 10.1249/ mss.0b013e31815a5181.

38. Waddington I, Malcolm D, Roderick M, Naik R. Drug use in English professional football. Br J Sports Med 2005;39(4):e18; discussion e18. doi: 10.1136/bjsm.2004.012468.

39. Sharma S, Drezner JA, Baggish A, et al. International recommendations for electrocardiographic interpretation in athletes. J Am Coll Cardiol 2017;69(8):1057-75. doi: 10.1016/j.jacc.2017.01.015. 